Journal of Contemporary Educational Research

Research Article

\title{
Innovative Research on Improving the Construction and Management Level of Computer Laboratories in Application-oriented Universities
}

Qunfang Zhang*

Zhejiang University of Finance and Economics Dongfang College. Haining 314408, Zhejiang Province, China

\begin{abstract}
Since the eighties of the last century, the international higher education community has gradually formed a trend of attaching importance to practical teaching and strengthening the cultivation of application-oriented talents. With the construction demand of application-oriented talents, the requirements for laboratory work in universities to be raised, the traditional laboratory construction environment equipment and the management mode can no longer satisfy the needs of modern education; there exist a lot of problems, such as old environment, aged equipment, backward management system and mode, weak service awareness etc., it needs to break the old management mode, adopting informatization management, normalizing management system, raising service awareness, strengthening the laboratory publicity, so that the overall level of computer laboratory construction and management would be improved.
\end{abstract}

Keywords: Application-oriented; Computer laboratory; Management level; Innovation research

Publication date: August, 2020

Publication online: 31 August, 2020

*Corresponding author: Qunfang Zhang, zhangqunfang0302@163.com

\section{Preface}

Since the eighties of the last century, a trend that attaches importance to practical teaching and strengthens the cultivation of application-oriented talents have been gradually formed all over the international colleges and universities. Many colleges and universities in China have also begun to explore and focus on practice to cultivate students' practical ability and innovative ability[1]. With the reform of education system and the demand for application-oriented talents, the requirements for laboratory work in colleges and universities are constantly improved, especially for computer laboratories as basic laboratories, not only to focus on the hardware environment of laboratory construction, but also to pay attention to the soft environment of laboratory construction, such as management system, management mode and the construction of management talents.

\section{Problems Existing in the Construction and Management of Computer Laboratories}

Computer laboratory is a basic laboratory for the construction of university laboratories, which mainly meets the teaching needs of computer courses. With the development of information technology, there are many problems in traditional computer laboratories, which can hardly meet the needs of modern educational technology mainly on the following aspects:

\subsection{Old Environment and Aged Equipment in Laboratories}

With the construction demand of application-oriented universities, at present a lot of colleges and universities focus on cultivating the practical ability of students, and a lot of experiments training courses will be carried out in many universities. As for the financial universities, the use of the computer lab is more and more wide and the frequency is higher and higher; as per the survey data of some universities, the use frequencies of computer lab is as high as $90 \%$, however; with the increasing years and frequencies of use for laboratories, the laboratory environment is older and older, which cannot meet the needs of current teaching. Although a 
large amount of laboratory funds will be input for maintenance and repair each year, the maintenance effect is barely satisfactory because of speeding updating for electronic equipment; as for the computer equipment ten years ago, its system function is not able to meet the current needs.

\subsection{Backward Laboratory Management Mode}

The traditional computer laboratory management method is very simple, which is carried out for the whole classroom inspection and computer equipment inspection before the semester, so that it can ensure the normal teaching at the beginning of the semester. Daily management and maintenance depends on the teachers' emergency calls, it can be directly remote solved in case of server and FTP problems, and someone will be sent to the classroom to solve in case of teachers' or students' computer problems. If there is any problem that can't be solved in class, it will be recorded and solved after class. As for the demand of software installation, generally the application form for installation is filled in at the end of the semester or the beginning of the semester. The laboratory technician will contact the teacher according to the application form and install the software in advance. The teachers who have other needs in class will come to the laboratory management office and give a necessary explanation before class, which will be solved accordingly. As the computer laboratory is also used for Computer Rank Examination, a systematic inspection will be carried out before each examination. From the perspective of arrangement, the daily management and maintenance of the laboratory are mainly completed, but the management mode is backward as well as the low management efficiency.

\subsection{Backward Laboratory Management System}

Reasonable and standardized laboratory management system is the institutional guarantee to ensure the orderly operation of the laboratory ${ }^{[2]}$. The laboratory of the Independent College has been completed for ten years, and the related management system for experimenter, experiment teacher and laboratory equipment has been established at the beginning of the construction, as the laboratory construction and equipment updates, setting the open management mode and so on, but the corresponding management system for laboratory system remains the same, and the overall system is backward, even lack of management system, such as lack of laboratory open management system, laboratory borrowing system, laboratory technical personnel assessment system, the collection and filing system of experimental, the laboratory technical personnel training system and the laboratory curriculum assessment system etc..

\subsection{Experimenter's Weak Sense of Service}

Laboratory technicians are the main part of the laboratory work, who mainly undertake laboratory construction and daily management and maintenance work. However, many colleges and universities attach importance to the construction of experiment teaching staff, lack of the attention of the laboratory technicians, leading to laboratory technician position inferior, as a result some technicians are not satisfactory with the status quo, and leave the laboratory to other department or other colleges through position recruitment or taking civil service examination. The technicians left are satisfied with the status quo, no caring about educational background and professional title as a monk cares nothing but tolling a bell each day as it comes. So the technicians left who are lack sense of service are only responsible for the daily teaching and test security, and they are not willing to explore a new management model and service measures.

\subsection{The Weak Publicity of Laboratory Work}

With the development of information and technology, more computer professionals are demanded in the fields such as artificial intelligence and the internet of things etc., which means that computer laboratories shoulder the responsibility of training professionals, and the leaders from universities and colleges need to pay more attention to computer laboratories. However, the laboratory technicians' work focus on laboratory equipment repair and maintenance work and ensure the smooth operation of the experimental teaching, a lack of publicity for the daily work; they don't know how to summarize their work, a serious lack of publicity for the laboratory. As a result the laboratory work for the universities and colleges is defined as routine maintenance work, which belongs to the auxiliary teaching work. As long as the teaching can be guaranteed and there is no teaching accidents, that's enough. The colleges don't pay attention to the laboratory and the construction funds of the modern computer laboratory are also not enough.

\section{Innovative Research on Laboratory Construction and Management Level}

\subsection{Modernization of Teaching Environment}

Due to the limitation of experimental sites and the construction demand of application-oriented universities and colleges, more and more teachers attach importance 
to experimental training teaching, resulting in the teaching reform of many courses focusing on experimental training teaching and the increase of experimental class hours, which makes more courses need to be completed in the computer laboratory. According to the current teaching arrangement, the teaching arrangement in the laboratory is full and $90 \%$ of the computer laboratories are in full day classes from Monday to Friday ${ }^{[3]}$. The improvement of teaching environment is related to the teaching efficiency and comfort of teachers and students. To strengthen the construction of modernization of teaching environment, the first step is the hardware construction, updating and rebuilding the computer laboratory, replacement of old furniture and floor, strengthening circuit and wires repair, adopting modern decoration style, ensuring the computer laboratory clean and tidy, improving the internal environment of computer laboratory, providing a good experience for the teachers and students; the second step is the construction of software, which is very important for improving the efficiency of laboratory management, strengthening the reform of the computer laboratory, adopting cloud desktop technology to replace the traditional protection card management mode, offloading CUP to realize the remote operation and management of the laboratory by technician, so that the more convenience for the management of the computer laboratory could be provided and the modern management could be achieved.

\subsection{Information Management Method}

With the modernization of computer laboratories, traditional management methods are no longer suitable for the current management need; in order to improve the level of teaching and scientific research management services, it is necessary to strengthen the application of information technology and new media technology. WeChat Official Account or information platform are used to conduct network office, complete the approval process of online borrowing and realize paperless office, saving time for teachers and students and improving work efficiency. The laboratory manager can check the classroom and equipment usage at any time, learning about the classroom and equipment utilization rate, giving a reasonable assessment on experiment equipment procurement requirement and maintenance requirement; on one hand the laboratory and equipment for higher utilization shall be strengthened for the maintenance frequency and guarantee the normal operation of the equipment, and on the other hand, as for the lower utilization laboratory and equipment, the analysis of the reason shall be carried out and constructive suggestions shall be put forward, so that the utilization of laboratory could be improved, setting up complaints and suggestions boxes, and the teachers and students can timely reflect the problems in the use process in the computer laboratory, while the designated person shall maintain and timely deal with the complaints, feed-backing to the related teachers and students.

\subsection{Standardize the Management System}

A sound management system is the guarantee of laboratory operation orderly. The standardized management system is the base of laboratory and experimental equipment management; only by establishing and perfecting the system can the laboratory operate effectively. With modernization and informatization of computer laboratory construction, the related management system should also be constantly updated, such as experimental personnel management system, the laboratory management system, the experimental student management system, the experiment teacher management system, experimental instrument and equipment management system, the laboratory safety management system, the experiment equipment borrowing system and laboratory borrowing system, etc., so that it can adapt to the modern laboratory and equipment management need. At the same time, the modern management systems, such as revisit system and feedback system, will be established to revisit and feedback the problems existing during the use of the laboratory and experimental equipment, so that the teachers and students can understand the dynamics of problem handling and improve their satisfaction.

\subsection{Proactive Service Sense}

The laboratory management has both management and service functions. The laboratory technicians should consider how to improve the management and service quality of the computer laboratory ${ }^{[4]}$. As technicians of the laboratory, we should improve the consciousness of service, transforming passivity into initiative, and actively enter the laboratory to pay attention to the problems encountered by teachers and students in class, to learn about the needs of teachers and students,so that they can be solved in a timely manner. In addition, a real-time treatment system for laboratory problems should be established, such as preparing a hotline and solving the problems online, so that the problems encountered by teachers and students in class or in self-study shall be timely solved. At the same time, a revisit system should be established, following up the problems of laboratory equipment registered in the laboratory record book, carrying out the revisit by telephone or online, giving necessary feedback to the problems that have been solved 
so as to provide teachers and students with a good service experience. Finally, a regular survey shall be conducted on the satisfaction of all teachers and students based on the laboratory services. A network questionnaire is designed and the survey results is calculated and disclosed. The problems concerned by teachers and students should be timely feedback,improving the service sense of experimenter and the satisfaction of teachers and students,

\subsection{Normalizing publicity work}

Laboratory work focus on the service work, processing laboratory equipment failure problems in class, daily repair and maintenance of equipment, laboratory safety management, etc., most of the work is real-time and most of the laboratory management personnel's major is computer and science, focusing on work earnestly, lack of reporting, result in the neglect by the leader and the leader has no knowledge of the laboratory ${ }^{[5]}$. Therefore, the publicity work of laboratory management and maintenance should be strengthened, normalizing the publicity of daily work and timely summarizing the work. In combination with the department's work functions, a series of characteristic activities should be carried out, such as revisit activity, laboratory safety training and publicity and laboratory culture construction activities; the publicity should be strengthened and the merits should be highlighted,so that the leaders for college and department can attach importance to laboratory construction and management.

\section{Summarize}

The construction, management and maintenance for computer laboratory has always gotten on the leaders' nerves in colleges and universities ${ }^{[6]}$. As the electronic product, especially for the computer update quickly, taking a great effort to build a computer laboratory, and it is used for two years, then it can not keep pace with the needs of the courses; it needs to be reconstructed, wasting a lot of resources, so how to effectively allocate the resource, improving the utilization efficiency of computer equipment, reducing the waste of resources, which is a subject worth studying for a long time. At the same time, the management and maintenance of computer laboratory should keep up with the requirements of the times, as the increasing demand for talent in the field of artificial intelligence, the internet of things technology and block chain technology, Colleges and Universities should make good use of computer laboratories to train outstanding talents which can better suited to the development of society.

\section{References:}

[1] Mazen K, Ossama A. Comment on: "Sexually acquired syphilis: Laboratory diagnosis, management, and prevention"'[J]. Journal of the American Academy of Dermatology, 2020, 82 (6)

[2] Joseph AV, Sumeska T. Combined Albuminuria and Estimated GFR Laboratory Reporting Affects Primary Care Management of CKD[J]. Kidney Medicine, 2020

[3] Physics - Geophysics; New Findings from China Earthquake Administration in the Area of Geophysics Reported (Laboratory Study On the Effects of Fault Waviness On Granodiorite Stickslip Instabilities)[J]. Journal of Physics Research, 2020

[4] Bui TD, Tsai FM, Tseng NL, et al. Effective municipal solid waste management capability under uncertainty in Vietnam: Utilizing economic efficiency and technology to foster social mobilization and environmental integrity[J]. Journal of Cleaner Production, 2020, 259

[5] Callan HBS, Maddisen NMA., Alicia RMS, et al. Implementation of a Blind Quality Control Program in a Forensic Laboratory[J]. Journal of Forensic Sciences, 2020, 65 (3)

[6] E. N. I. Weeks, S. A. Allan, S. A. Gezan, P. E. Kaufman. Autodissemination of commercially available fungal pathogens in a laboratory assay for management of the brown dog tick Rhipicephalus sanguineus[J]. Medical and Veterinary Entomology, 2020, 34 (2) 